\title{
Da Diáspora à Palestina: novas concepções sobre a localização dos evangelhos sinóticos
}

\author{
Marcelo da Silva Carneiro ${ }^{1}$
}

\section{RESUMO}

Este artigo pretende mostrar as mudanças teóricas sobre a localização dos evangelhos sinóticos. O objetivo é demonstrar como a localização dos evangelhos sinóticos foi por muito tempo fundamentada na Tradição, e não em análise contextual. Desde os Pais da Igreja os evangelhos sinóticos foram situados em diferentes pontos do império romano, em geral fora da região siro-palestinense. Novas tendências, no entanto, tem demonstrado que Marcos, Mateus e Lucas pertencem a um gênero literário vinculado ao mundo judaico da Palestina, e seus evangelhos refletem essa proximidade cultural. A partir disso é possível chegar a duas conclusões principais: por um lado, os evangelhos sinóticos surgiram para responder a demandas de comunidades judaico-cristãs que estavam em situação de crise e usaram a memória sobre Jesus para dar fundamento às suas respostas. Por outro lado, as novas tendências indicam a proximidade entre o cristianismo primitivo e o judaísmo, como expressão da pluralidade deste.

\section{PALAVRAS-CHAVE}

Cristianismo Primitivo. Teoria Literária. Evangelhos Sinóticos. Tradição Oral.

${ }^{1}$ Doutorando em Ciências da Religião pelo Programa de Pós-Graduação da UMESP, bolsista CNPQ. 


\begin{abstract}
This paper seeks to demonstrate the theoretical changes related to the Synoptic Gospels locus. It shows that the Synoptic Gospels locus is based only in Tradition, and not in contextual analysis. Since the Church Fathers, the Synoptic Gospels are located in different places of the Roman Empire, generally in the Syria-Palestinian area. New tendencies, however, show that Mark, Matthew and Luke belong to a literary genre of the Palestinian Judaic world, and that their Gospels reflect this cultural proximity. Considering that, it is possible to conclude two principal points: firstly, the Synoptic Gospels emerged in response to Judaic-Christian community demands in a crisis situation and used Jesus' memories to ground their answers. Secondly, the new tendencies link the proximity between the Primitive Christianity and Judaism. Primitive Christianity is an expression of the plurality of the Judaism..
\end{abstract}

\title{
KEYWORDS
}

Early Christianity. Literary Theory. Synoptic Gospels. Oral Tradition.

\section{Introdução}

A pesquisa sobre os evangelhos sinóticos tem discutido alguns temas: os evangelhos foram escritos para uma comunidade específica ou eram propaganda para todos que tivessem acesso e lessem o texto? Qual a datação mais adequada para eles? O que representa o gênero evangelho no contexto judaico-romano? Mas não há uma pesquisa abrangente que envolva os três sinóticos na questão geográfica. Este artigo deseja mostrar um pouco as pesquisas sobre o tema e apontar uma teoria geográfica contextual para os sinóticos.

\section{A localização dos evangelhos segundo a pesquisa tradicional}

Desde meados do século 20, a pesquisa definiu um consenso que aponta uma localização para os evangelhos, quando se começou a pensar na importância de determinar o contexto original de cada um deles. A base dessa posição 
era o estudo da crítica da redação, a partir da Redaktiongeschichte (História ou Crítica da Redação), "aplicada por primeiro por Bornkamm, 1948, ao evangelho de Mateus e por H. Conzelmann (1954), a Lucas"2. A crítica da redação estabeleceu a ideia de que os evangelistas não são meros copistas, mas que interferiram nas tradições e fontes as quais tiveram acesso, ou seja, a partir dos escritos é possível perceber a história do texto e o objetivo com que ele foi escrito. Considerando o conjunto das narrativas e baseados na tradição da patrística indicaram como local de origem Roma para o Evangelho de Marcos, Síria para Mateus e Grécia para Lucas.

A data da origem do Evangelho de Marcos como texto final é fixada pela opinião tradicional como resultado de uma tradição petrina em Roma, no período entre 40-70 d.C. O foco está na relação de Marcos com o apóstolo, e a importância da Igreja de Roma como um dos principais centros do cristianismo, além de ser a capital do império. Posteriormente, outros pesquisadores deslocaram o lugar para um ponto oriental do império, mas não aventaram a possibilidade da Palestina. A tradição que Papias apontou, na citação de Eusébio de Cesareia, afirma que Marcos recebeu os relatos de Pedro, que a essas alturas já era associado a Roma, onde foi executado nos anos entre 62-64 d.C. ${ }^{3}$ No entanto, essa posição é incerta e questionada por uma boa parte dos pesquisadores, mesmo considerando os latinismos e a relação do texto com Pedro. Para Kümmel, não há evidências que sustentem uma redação em Roma, sendo assim, trata-se de um texto composto a partir de "uma comunidade cristã oriental composta de gentios"4. É o que pensa igualmente Koester, que defende uma redação numa metrópole oriental, visto que se o evangelho é fundado na autoridade de Pedro, "provavelmente mais na Síria do que em Roma, e latinismos podiam ocorrer onde quer que uma guarnição romana estivesse estacionada e uma administração romana provincial fosse instalada"5. Mesmo assim, ele sugere a cidade de Antioquia para a redação de Marcos.

Mateus tem diversos elementos que o aproximam de uma origem judaica: a divisão em cinco discursos, assemelhando-se a um Pentateuco

\footnotetext{
2 KÜMMEL, W. G. Introdução ao Novo Testamento, p. 54.

3 KOESTER, Helmut. Introdução ao Novo Testamento, p. 182.

4 KÜMMEL, W. G. Introdução ao Novo Testamento, p. 117.

${ }^{5}$ KOESTER, Helmut, Introdução ao Novo Testamento 2, p. 182.
} 
de Jesus; um estilo escribal muito próximo daquele desenvolvido na $\mathrm{Pa}$ lestina; muito mais textos tratando sobre a discussão a respeito da observância da Lei (cf. 5.17) do que os demais evangelistas, além da evidência externa de Papias que o associa a um texto aramaico mais primitivo. Por tudo isso, Mateus tem sido o evangelho mais associado a um background judaico ${ }^{6}$. Mesmo assim a crítica o localizou na Síria, em alguns casos na cidade de Antioquia. Contudo, seus argumentos não se sustentam numa análise que coloca a mensagem do evangelho mateano diante do judaísmo formativo, talvez até um grupo farisaico em conflito com os demais.

Dentre os que sustentam a posição na Síria, podemos citar Fernando Camacho e Juan Mateos, autores do comentário mateano El Evangelio de Mateo - lectura comentada (1981), que não excluem a possibilidade de uma origem palestinense, mas afirmam que Antioquia seria a mais provável, porém eles firmam essa localização sem maiores fundamentos $^{7}$. Eduard Schweizer, no comentário Das Evangelium nach Matthäus (1986), coloca o evangelho na Síria, por "il legame com il giudaismo

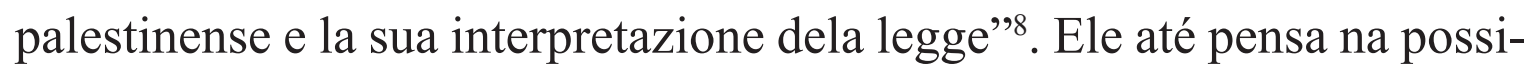
bilidade de uma origem galileia, mas a presença de Pedro em Antioquia o faz considerar este como o local mais adequado. Ulrich Luz, no seu grande comentário Das Evangelium nach Matthaus (1990), se fundamenta no fato de que, se Marcos foi escrito para um público restrito, próximo a Roma, então Antioquia seria adequado para Mateus escrever um Evangelho mais universal ${ }^{9}$.

Mais recentemente, Warren Carter, no seu comentário sociopolítico de Mateus, Matthew and the Margins: A Sociopolitical and Religious Reading (2000), defende Antioquia como lugar social do Evangelho, apesar de declarar que não "podemos estar completamente seguros sobre

6 JOHNSON, Sherman E. “The Gospel According to St. Matthew". In: Interpreter's Bible. Vol. VII, p. 239ss; GARCIA, Paulo R. Sábado: a mensagem de Mateus e a contribuição judaica, p. 8ss; WILLS, Lawrence M. "Scribal Methods in Matthew and Mishnah Abot". In: The Catholical Biblical Quaterly, p. 241-257. Luz reforça a tese de um ambiente judaico, ao afirmar que "el evangelio de Mateo surge cuando esta comunidade judeocristiana se encontraba en una encrucijada." EI Evangelio Según San Mateo, I, p. 85.

7 CAMACHO, Fernando, MATEOS, Juan. O Evangelho de Mateus, p. 10.

8 SCHWEIZER, Eduard. Il Vangelo secondo Matteo, p. 15.

9 LUZ, Ulrich. El Evangelio Según San Mateo I, p. 85-86. 
onde foi escrito"10. Seu argumento se baseia no papel de Pedro, e nas citações de Inácio de Antioquia, que mostram uma familiaridade maior com Mateus. Koester também defende a Síria, e fundamenta sua tese na autoridade de Pedro em Antioquia, e a controvérsia com o judaísmo não permitem "uma localização não muito longe da Palestina"11. Isidoro Mazzarolo, em seu comentário Evangelho de São Mateus (2005), afirma que "o ambiente é claramente de tradição judaica" e que "a oposição e as polêmicas com as tradições sugerem um lugar onde houvesse judeus que passavam para o cristianismo com enormes dificuldades em virtude da resistência dos grupos e oposição"12. O que se percebe nesses autores, bem como em vários outros, é que a defesa pela Síria se baseia na tradição, mais que evidências internas do texto e de contexto histórico. Apesar disso, em todos esses autores há o consenso, junto com os que defendem a Galileia como lugar de composição, que o Evangelho foi escrito após o ano 70 d.C.

Em relação ao locus da obra lucana, admite-se uma formação em Lucas que o aproxima de Antioquia, onde o diálogo com a influência da cultura helenística é muito forte. Além disso, há na obra lucana muitos termos exclusivos, em relação aos demais evangelistas, bem como termos emprestados da LXX, aramaísmos, hebraísmos e semitismos diversos, o que confere ao texto um teor cultural complexo, para atender a um público misto, com fluência no grego, mas que não desconhecia a dinâmica da língua quando entra em contato com outras culturas. Mesmo assim, o consenso na pesquisa situa a obra lucana na Grécia, ou no máximo na Ásia Menor, como subproduto da escola paulina, associando o autor do complexo com o Lucas citado por Paulo em Filemon 24.

\section{A crítica ao consenso da pesquisa tradicional}

Recentemente essa posição sobre o consenso da pesquisa foi questionada por outros pesquisadores, como Richard Bauckham ${ }^{13}$, sob duas alegações:

\footnotetext{
${ }^{10}$ CARTER, Warren. O Evangelho de Mateus, p.34ss

${ }^{11}$ KOESTER, Helmut. Introdução ao Novo Testamento 2, p. 188.

12 MAZZAROLO, Isidoro. Evangelho de São Mateus, p. 5.

${ }^{13}$ BAUCKHAM, Richard. The Gospel for All Christians, 1998.
} 
(1) a tese tradicional só se apoia no consenso que foi elaborado com o tempo, sem buscar uma argumentação fundamentada nos textos. Mesmo com o desenvolvimento da pesquisa sob a dimensão histórico-social, não se pergunta em que circunstâncias essas comunidades poderiam subsistir isoladas do restante do cristianismo, ou seja, porque os evangelhos teriam sido escritos apenas para uma comunidade, de maneira isolada.

(2) a segunda alegação de Bauckham tem a ver com o sistema de comunicação no império romano entre as comunidades cristãs, desde o período de Paulo. Elas não eram comunidades isoladas e autossuficientes, mas uma rede de comunidades com constante comunicação entre elas. A partir dessas duas alegações Bauckham conclui que os evangelhos não foram escritos para responder a questões específicas de algumas igrejas, mas já nasceram como textos abertos, voltados para todos os cristãos que tivessem acesso a eles. Além disso, Bauckham reforça bastante que o gênero Evangelho é diferente do gênero Epistola, este sim voltado para um grupo específico, como o próprio texto indica.

A posição adotada neste artigo concorda com Bauckham em alguns aspectos: as teorias tradicionais se apoiaram mais no consenso do que em análises próprias de cada evangelho; as comunidades cristãs realmente se comunicavam e não eram isoladas, diferente do que apontam os estudos sobre cada evangelho visto isoladamente; o gênero Evangelho é diferente do gênero Epístola, principalmente porque não tem destinatário expresso. Curioso também é que Bauckham aceita a antiguidade de Marcos sobre os demais evangelhos, sem fundamentar sua posição.

$\mathrm{Na}$ verdade, a abordagem adotada neste artigo considera importante e possível apontar as comunidades que geraram os evangelhos sinóticos, mesmo compreendendo que, com a comunicação entre as diferentes comunidades cristãs, em pouco tempo eles foram aceitos como textos inspiradores para outros cristãos, como já havia acontecido anos antes com os textos paulinos.

Para que a teoria tradicional sobre os evangelhos terem sido escritos para comunidades específicas faça sentido, é preciso pensar neles como resultado de um processo cultural e social relacionado com a realidade de 
cristãos que guardaram a memória sobre a vida de Jesus de Nazaré. Ou seja, comunidades próximas geograficamente da Galileia e Judeia, onde o judaísmo não era apenas mais uma religião, mas onde se destacava como uma religião muito praticada. Com a comunicação entre as diferentes comunidades cristãs, em pouco tempo eles foram aceitos como textos inspiradores para outros cristãos, como já havia acontecido anos antes com os textos paulinos. Bauckham só consegue manter seu argumento contrário ao consenso porque pensa nos textos dos evangelhos nascidos em diferentes lugares do império romano, em geral dentro da diáspora.

\section{As novas tendências sobre a localização dos evangelhos}

A solução apontada aqui tem seu embasamento em novas pesquisas sobre os evangelhos que, juntas, formam um quadro coerente sobre o cristianismo primitivo que originou o gênero evangelho. Para fazer sentido que os evangelhos tenham sido escritos para comunidades específicas, é preciso pensar neles como resultado de um processo cultural e social relacionado com a realidade de cristãos que guardaram a memória sobre a vida de Jesus de Nazaré, diferente do que aconteceu na diáspora, onde as epístolas foram o meio de divulgação da mensagem cristã. Ou seja, comunidades próximas geograficamente da Galileia e Judeia, onde o judaísmo não era apenas mais uma religião, mas onde se destacava como uma religião muito praticada. Assim, os evangelhos são a maneira judaica de responder às novas questões geradas nas comunidades cristãs da Palestina.

A tese de que os Evangelhos estão vinculados à Palestina se apoia em diferentes pesquisadores, que avaliaram cada um deles de forma separada. Para Marcos podemos apontar Ched Myers e Marie N. Sabin. Para Mateus, Anthony Saldarini, Andrew Overman e Paulo Roberto Garcia. E para Lucas, as pesquisas de Wayne Meeks e Magnus Zetterholm. $\mathrm{O}$ deslocamento da localização das comunidades para a região siro-palestinense resolve uma série de questões abertas que a pesquisa mais tradicional não respondia, e que a posição de Bauckham não levou em conta. Por outro lado, estudar os evangelhos sinóticos em conjunto permite perceber melhor a dinâmica da formação dos textos e a identidade das comunidades por trás deles. 
Sobre a antiguidade e localização de Marcos

Helmut Koester, em seu trabalho introdutório do Novo Testamento, procurou demonstrar uma teoria confiável para as fontes de Marcos. Em Introduction to the New Testament: History and Literature of the Early Christianity (1995), Koester fez um levantamento da formação literária dos escritos do Novo Testamento, vinculados ao contexto sociocultural no qual se originaram. No caso dos evangelhos sinóticos, ele os trata a partir de tradições agrupadas ao movimento cristão inicial, iniciando pela problematização referente às fontes e teorias literárias. A teoria da formação dos evangelhos é tratada por ele de forma complexa, considerando as etapas de coleções e, posteriormente, agrupamentos literários que geraram os livros, tendo Marcos e Q como fontes primárias para Mateus e Lucas, além de outras fontes para esses últimos.

Especificamente sobre as fontes de Marcos, Koester afirma que devem ter havido diversas, entre elas: a narrativa da Paixão (Mc 11.1-16.8), uma fonte também utilizada por João; a fonte dos milagres, que compartilha duas narrativas presentes na fonte dos sinais joanino, e pouco material de ensino, que teria valor secundário na perspectiva de Marcos, que em alguns casos, onde há paralelismo com Q, devem ser acolhimento de tradição oral de ditos isolados. Por outro lado, ensinos com maior volume de material (como as parábolas em Mc 4 e o Apocalipse Sinótico, em Mc 13) devem ter advindo de fontes escritas ${ }^{14}$. Esse seria um dos primeiros indícios de origem palestina: o acesso a fontes orais ou escritas que surgiram naquela região, poucos anos antes do evangelho surgir como escrito final.

Sobre a data da origem do Evangelho de Marcos como texto final, a pesquisa mais recente apoia uma datação entre 65-70 d.C., ou seja, no período da Guerra Judaico-Romana que culminou com a destruição de Jerusalém ${ }^{15}$. Essa datação expressa bem o estilo enxuto e ríspido do

${ }^{14}$ KOESTER, Helmut. Introdução ao Novo Testamento 2, p.182-183.

15 A datação de c. de 40 d.C. é proposta por CROSSLEY, James A. Em sua obra The Date of Mark's Gospel: Insight from the Law in Earliest Christianity. London/ New York: JSNTSup, 2004, o autor defende uma datação mais antiga pela discussão em torno da observância da Torá presente no livro. Uma datação mais próxima do ano 70 d. C. é defendida por vários autores, dentre eles GRANT, Frederick C. 
Evangelho de Marcos; nele, Jesus não tem muito tempo para grandes discursos nem meditações, mas uma ação enérgica que mova a consciência das pessoas rumo à grande revelação: "Jesus Cristo é o Filho de Deus", tema que abre (1.1 - afirmação do narrador) e praticamente fecha (15.39 - declaração de um centurião diante da cruz) a obra ${ }^{16}$.

Alguns pesquisadores, assumindo essa nova abordagem, têm situado o evangelho na Galileia. É o caso de Ched Myers, no seu comentário ao Evangelho de Marcos, que afirma haver diversos indícios no texto para apontar uma localização na Palestina Setentrional, provavelmente na Galileia, nos anos da revolta judaica, entre 66-70. Para ele

uma data anterior a 70 e durante a revolta (portanto, depois de 66) é essencial à coerência da ideologia política e econômica da narrativa de Marcos. A forte crítica que Marcos lança ao estado do templo e à sua economia política teria evidentemente sido supérflua se o templo já houvesse sido destruído ${ }^{17}$.

Outra autora que reforça essa tese é Marie N. Sabin. Em sua obra Reopening the Word. Reading Mark as Theology in the Context of Early Judaism (2002), ela aponta alguns elementos que parecem corroborar com essa posição: (1) em Marcos há um diálogo com a cultura helênica, ao mesmo tempo em que há uma discussão sobre a interpretação da Torá, típica da literatura judaica palestinense; (2) o estilo tenso do texto, narrando muitas vezes o conflito em narrativas curtas, aponta para a necessidade de tê-lo pronto, frente a eventos calamitosos que parecem estar prestes a acontecer (no caso, a Guerra Judaico-Romana já está em andamento, e a percepção de que Jerusalém será destruída parece já estar

“The Gospel According to St. Mark". In: The Interpreter's Bible. Vol VII, p.630s; KÜMMEL, W. G. Introdução ao NT, p. 117; KOESTER, Helmut. Introdução ao Novo Testamento 2, p. 182 (apesar de que ele pensa numa datação ainda mais tardia, entre 70 e 80$)$.

${ }^{16}$ MARCONCINI, Benito. Os Evangelhos Sinóticos, p. 97-98.

${ }^{17}$ MYERS, Ched. O Evangelho de São Marcos, p. 68. Apesar da ênfase no aspecto político da formação do Evangelho de Marcos - fator que não pode ser desconsiderado, mas que não é nosso foco principal na pesquisa - Myers tem uma excelente introdução geral ao evangelho, que explora com profundidade o mundo social da Palestina do século 1 d.C. 
no horizonte dos judeus palestinenses); (3) não há relação com a teologia paulina, que a essas alturas era bastante divulgada na Ásia Menor, Macedônia e Itália; (4) o estilo de Marcos transparece tradução do aramaico, e no seu texto existe uma dubiedade: um grego cru em narrativas bem elaboradas ${ }^{18}$.

Quanto ao problema das descrições erradas da geografia palestinense (como no caso de Gerasa em Mc 5.1ss, que parece estar ao lado do Lago de Genesaré - ou Mar da Galileia - e na verdade ficava a $40 \mathrm{~km}$ do local), deve-se ter em conta que a geografia no Evangelho de Marcos tem um sentido teológico. Ele não quer descrever historicamente o percurso de Jesus, mas apontar os efeitos da pregação do Messias nos diversos lugares, em especial na Galileia. Kümmel reforça a tese da dimensão teológica da geografia, ao afirmar que "se é permitido concluir que foi o próprio Marcos quem criou o itinerário de Jesus, então é preciso também admitir que a grande concentração da atividade de Jesus na Galileia teve origem em algum motivo de ordem teológica"19. E aqui pensamos também se não seria motivado pela própria origem da comunidade receptora do Evangelho, no caso algum ponto na Galileia.

Considerando o texto na perspectiva de narrativa identitária da comunidade de crentes em Jesus diante das vertentes judaicas com as quais convivem, uma localização na Galileia é bastante considerável. Partindo desse ponto, pode-se pensar que o processo de transmissão do dito de Jesus para a comunidade tenha tido um início pela tradição oral, onde pequenas histórias de fácil memorização - por sistemas mnemônicos com um fim enfático eram bastante comuns, passando por uma fixação por escrito anos depois, de forma fragmentada, até chegar ao Evangelho de Marcos, onde a narrativa está a serviço de um objetivo geral, dentro

${ }_{18}$ SABIN, Marie N. Reopening the Word. Reading Mark as Theology in the Context of Early Judaism. Oxford: Oxford University Press, 2002, p.7-8. SOARES, Sebastião Armando Gameleira. Marcos, também admite essa hipótese, mesmo sem discutir com mais profundidade. Ele apenas indica que "estaria apoiado na importância dada pelo autor à geografia e, sobretudo, ao significado teológico da Galileia, como terra helenizada, de cujo seio nasce o movimento de Jesus", p. 15.

${ }^{19}$ KÜMMEL, W. G. Introdução ao Novo Testamento, p.102. Assim como alguns autores defendem uma visão teológica da história por parte de Marcos. Cf. NÚÑEZ, César Carbullanca. "Apuntes sobre el sentido teológico de la historia en el Evangelio de Marcos". In: Oracula 4.8 (2008). 
da qual ele é inserido com intencionalidade ${ }^{20}$. Assim, o texto de Mc 2.2328 pode ter sido um escrito primitivo, uma fixação literária da tradição dos logia de Jesus, antes mesmo de fazer parte efetivamente do Evangelho canônico, provavelmente em grego mesmo, tendo em vista que o idioma já era difundido em toda a região desde o século 3 a.C.

Assim, pode-se pressupor uma comunidade mista, de cunho judaico, mas com membros oriundos dos grupos estrangeiros residentes na Galileia, a serviço de Roma, onde o grego era a língua comum, mas o sentimento de pertença à cultura judaica ainda era muito forte, mesmo com as diferenças em relação a outros grupos. Na mente dessa comunidade, uma verdade: Jesus Cristo é o Filho de Deus, expressão colocada na boca de um Centurião no momento da morte de Jesus, não por acaso.

\section{Sobre a localização de Mateus}

Temos como pressuposto que Mateus teve Marcos como fonte seja o texto canônico ou um texto primitivo de Marcos - e que reelaborou esse material. Além disso, Mateus utilizou outras fontes, sendo que uma delas também foi usada por Lucas, a fonte chamada $Q^{21}$. Uma informação curiosa a respeito de Mateus é a citação de Papias presente na História Eclesiástica de Eusébio de Cesarea $^{22}$. Ele afirma que o evangelho canônico é uma tradução para o grego de um texto mais antigo, em aramaico. Entretanto, seja por falta de evidências materiais, ou mesmo por questões de estilo, nada pode se afirmar a respeito. Koester levanta

${ }^{20}$ Sobre isso ver o pensamento de KOESTER, Helmut, Introdução ao Novo Testamento 2, p. 183-184; GRANT, Frederick C., GRANT, Frederick C. "The Gospel According to St. Mark", p. 630-631, e que podem explicar os casos onde Mateus e Lucas concordam entre si, enquanto o texto de Marcos difere de ambos. Nesse caso, teriam eles tido contato com o texto mais primitivo de Marcos, segundo a hipótese defendida por Koester, p. 183.

${ }^{21}$ Segundo KOESTER é "o testemunho mais importante para a teologia escatológica das comunidades que transmitiram as palavras de Jesus", Introdução ao Novo Testamento 2, p.162. Teria sido composto ainda pelo ano 50 d.C. "com base em coleções porventura existentes de ditos que haviam sido reunidos para fins catequéticos, polêmicos e homiléticos." Idem.

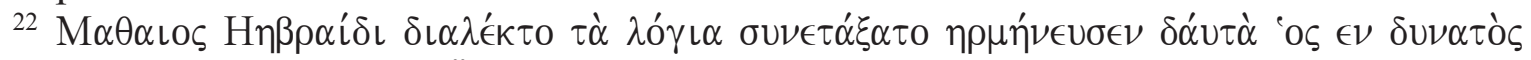

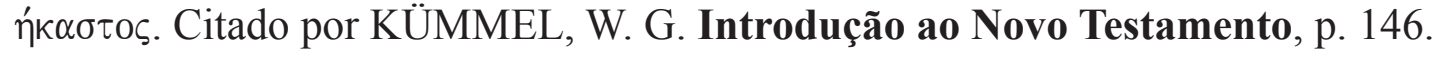


também a ideia de que poderia se tratar de um original aramaico do Evangelho de Ditos Q, similar aos Ditos de Tomé. Nesse caso, o que se pode pensar é na existência prévia de materiais em aramaico que teriam sido traduzidos sob a autoridade de Mateus ${ }^{23}$. Essa controvérsia sobre Mateus tem que levar em consideração ainda o material próprio que só consta em sua obra, nada desprezível, pois é a mesma quantidade de versículos que ele compartilha com Marcos (330).

Já comentamos o pano de fundo judaico do evangelho de Mateus. Considerando a situação da Galileia após o ano 70 d. C., com o florescimento de escolas rabínicas e até mesmo dos ensinos que futuramente formarão a Mishná, pode-se considerar a hipótese do Evangelho de Mateus ter nascido na Galileia, anos após o Evangelho de Marcos, pelo menos entre 80-90 d. C. Andrew Overman realizou uma extensa pesquisa em que demonstra que o judaísmo presente em Mateus está diretamente relacionado à sua localização na Galileia ${ }^{24}$, tese que Paulo Garcia acompanha em sua pesquisa sobre o Sábado, na qual afirma:

A argumentação para apoiar a tese da origem na Galileia, encontra respaldo no fato de que o Jesus de Mateus tem seu ministério desenvolvido somente na Galileia, exceto, logicamente, nos relatos da Paixão. É importante destacar, também, que o desenvolvimento da tradição rabínica - oposição de Mateus - teve nesses dois lugares focos importantesde desenvolvimento. Figuras como o rabino Iohanan Ben-Zakai, Rabi Judá e outros importantes líderes do período formativo do judaísmo rabínico são identificados, diretamente, com a Galileia ${ }^{25}$.

Anders Runesson, no artigo "Rethinking Early Jewish-Christian Relations: Matthean Community History as Pharisaic Intragroup Conflict" (2008), chega a defender que a terminologia mais adequada para a comunidade de Mateus seria de um “judaísmo apostólico" e que, mesmo assim, haveria diversas vertentes, razão porque propõe um judaísmo

${ }^{23}$ KOESTER, Helmut. Introdução ao Novo Testamento 2, p.188-189.

${ }^{24}$ OVERMAN, J. Andrew. O Evangelho de Mateus e o Judaísmo Formativo. São Paulo: Loyola, 1997.

${ }^{25}$ GARCIA, Paulo R. Sábado: a mensagem de Mateus e a contribuição judaica, p. 30. 
mateano para singularizar essa vertente. Ele também defende a Galileia como lugar da composição do evangelho, provavelmente em Séforis ${ }^{26}$. Também Saldarini e Overman, já citados anteriormente, desenvolvem a ideia do evangelho mateano na Galileia, a partir do conflito com os grupos judaicos. Ou seja, se a comunidade de Mateus é intrajudaica, o lugar mais plausível para o conflito seria na Galileia.

O estilo mais aproximado de uma estrutura literária bem desenvolvida, com seus cinco discursos, sugere uma comunidade de ouvintes-leitores mais requintados, talvez com um grupo de alfabetizados, provavelmente situado numa cidade maior da Galileia, talvez Séforis ou Tiberíades, considerando sua linguagem e provável público receptor ${ }^{27}$.

Sobre a localização de Lucas

O Evangelho de Lucas é, na verdade, a primeira parte de uma obra maior, em conjunto com o livro dos Atos dos Apóstolos. Acredita-se que inicialmente era uma obra única, mas pela extensão dela foi seccionada em duas, com um arranjo redacional no fim do Evangelho e no início de Atos, a fim de criar a vinculação entre as obras, ao mesmo tempo que é possível lê-las separadamente ${ }^{28}$.

Segundo alguns autores, é também o evangelho mais próximo da tradição paulina, em termos de perspectiva da salvação e ação do Espírito sobre a comunidade. Segundo Koester, no fim do discurso da destruição do templo, repleto de detalhes que Marcos não tem, "se encontram algumas advertências escatológicas, reminiscentes da terminologia de Paulo (21,34-36)"29. Por outro lado o destaque dado a Paulo em Atos dos Apóstolos sugere no mínimo uma admiração pela autoridade apostólica de Paulo. Entretanto, Fitzmyer lembra que o Paulo de Atos é bastante

${ }^{26}$ RUNESSON, Anders. "Rethinking Early Jewish-Christian Relations: Matthean Community History as Pharisaic Intragroup Conflict". In: Journal of Biblical Literature, p. 95-132.

${ }^{27}$ OVERMAN, J. Andrew. O Evangelho de Mateus e o Judaísmo Formativo, p. 158; LIMA, Anderson de O. Acumulai tesouros no céu: estudo da linguagem econômica no Evangelho de Mateus, p. 37-55.

${ }^{28}$ KOESTER, Helmut. Introdução ao Novo Testamento 2, p.328-329.

${ }^{29}$ KOESTER, Helmut. Introdução ao Novo Testamento 2, p. 337. 
distinto do retrato que o apóstolo faz de si mesmo nas cartas, e por isso mesmo Lucas foi considerado inferior teologicamente ao suposto patrono. Fitzmyer também questiona essa afirmação, pela importância de Lucas no cânon do NT, mais de um quarto do seu conteúdo ${ }^{30}$. Esse foi um dos motivos pelos quais o material lucano foi localizado num ambiente ocidental, provavelmente numa das igrejas fundadas por Paulo.

Quanto à datação, Fitzmyer afirma que há bastante controvérsia: por causa do final de Atos, com o apóstolo Paulo ainda vivo, diversos pesquisadores do século XX afirmaram uma data anterior a 70, ou ainda a 60 d.C., como, por exemplo, Jerônimo, F. Blass, J. Cambier, L. Cerfaux, E. E. Elias, A. von Harnack, W. Michaelis, J. A. T. Robinson, dentre outros ${ }^{31}$. O problema está na reelaboração do Sermão Apocalítico de Mc 13, que dá detalhes sobre a destruição de Jerusalém ausentes no primeiro evangelho. Porém, mesmo assim C.H.Dodd trabalha com uma hipótese de datação antiga, e justifica afirmando que é "una composición personal, tejida enteramente de expresiones veterotestamentarias" 32 . Como Fitzmyer soluciona o problema? Primeiro, aponta a surpresa dos pesquisadores ante a escassez de informações sobre a destruição de Jerusalém nos evangelhos, tendo em vista a importância desse fato para os judeus da Palestina. Em segundo lugar, mesmo considerando a possibilidade de que os evangelistas tenham tido acesso independente às fontes - o que Fitzmyer tem dificuldade em aceitar - ou numa proposta da teoria das duas fontes modificada, deve-se levar em conta a releitura lucana para as narrativas de Marcos (o que a obra de Orton, indicada acima, demonstra claramente). Por fim, Fitzmyer analisa que o final de Atos não se preocupa com os acontecimentos posteriores a Paulo, e seu autor se considera satisfeito por narrar a história das comunidades cristãs da origem até sua prisão. Por tudo isso, ele considera a melhor datação, como posterior a 70 d.C., e antes do século 2 d.C. Assim, ele aceita a datação mais corrente de 80-85 para a obra lucana ${ }^{33}$.

${ }^{30}$ FITZMYER, Joseph A. Evangelio Según Lucas, I, p.59-60.

${ }^{31}$ FITZMYER, Joseph. Evangelio Según Lucas I, p.101-102.

32 DODD, C.H. Apud FITZMYER, Joseph. Evangelio Según Lucas I, p. 102.

${ }^{33}$ Outros que concordam com essa datação: Werner G. Kümmel (Introdução ao Novo Testamento, p.188.), Helmut Koester (Introdução ao Novo Testamento 2, p. 332. Porém, ele admite uma data posterior, no início do século 2.), Eduard Lohse (Introdução 
Em relação ao locus da obra lucana, Joseph Fitzmyer admite uma formação em Lucas que o aproxima de Antioquia, onde o diálogo com a influência da cultura helenística era muito forte ${ }^{34}$. Além disso, há na obra lucana muitos termos exclusivos, em relação aos demais evangelistas, bem como termos emprestados da LXX, aramaísmos, hebraísmo e semitismos diversos, o que confere ao texto um teor cultural complexo, para atender a um público misto, com fluência no grego, mas que não desconhecia a dinâmica da língua quando entra em contato com outras culturas $^{35}$. Será que Antioquia pode ser o lugar da comunidade de Lucas?

Para buscar uma resposta à essa questão, vale a pena considerar as pesquisas de Wayne E. Meeks e Robert L. Wilken, Jews and Christians in Antioch in the First Four Centuries of the Common Era (1978). Ali, quando trata do início do movimento cristão na cidade de Antioquia, Meeks aponta para Atos e Gálatas como fontes para apresentar esse quadro inicial. Mesmo com diferenças entre as narrativas, há indícios em Atos de eventos que não devem ter sido criados por Lucas. O episódio em que os discípulos foram chamados de cristãos ali pela primeira vez (cf. At 11.26), por exemplo, aponta para uma situação bastante verossímil, mesmo que o fato talvez não tenha se dado num primeiro momento, mas posteriormente, próximo ao ano 70, quando a guerra contra os judeus aumentou o sentimento antijudaico na cidade e os cristãos buscaram se distinguir deles ${ }^{36}$. Meeks nada fala sobre a identidade da comunidade cristã ali, ou seja, não relaciona essa comunidade com algum evangelho, a não ser com o relato de Atos em Lucas. Se Atos faz parte do conjunto da obra lucana, e Antioquia é o ponto de partida da missão paulina aos gentios, então é significativa a situação da comunidade. Além disso, Meeks entende que a lista de lideranças em At 13.1ss, de "profetas e mestres", tem um substrato histórico ${ }^{37}$.

Mais recentemente, outro pesquisador que estudou as origens dos cristãos em Antioquia foi Magnus Zetterholm. Em The Formation of

ao Novo Testamento, p.163.), e mais recentemente Paulo Lockmann (Jesus, o Messias Profeta (Lucas 9.51-19.48), p. 20).

${ }^{34}$ FITZMYER, Joseph A. Eı Evangelio Según Lucas I, p. 183.

${ }^{35}$ FITZMYER, Joseph A. EI Evangelio Según Lucas I, p.183-209.

${ }^{36}$ MEEKS, Wayne E., Jews and Christians in Antioch, p. 15-18. Essa posição sobre o afastamento com os judeus é de William Farmer, mas Meeks está de acordo com ela.

${ }^{37}$ MEEKS, Wayne E. Jews and Christians in Antioch, p. 15. 
Christianity in Antioch. A social-scientific approach to the separation between Judaism and Christianity (2003), ele faz um caminho similar ao de Meeks, mas estabelece o método de interpretação hermenêutica como base para analisar textos antigos, tanto os do Novo Testamento como extrabíblicos. Além disso, faz uma abordagem a partir de teorias sociais usadas em estudos de sociedades modernas, na busca da construção de um modelo de cidade romana onde diferentes grupos interagem. Zetterholm reconhece a complexidade do processo de separação do cristianismo e judaísmo, mesmo assim entende que é possível chegar a uma teoria consistente. Mesmo assim, também não identifica sua teoria com nenhuma comunidade geradora de um dos evangelhos.

Baseado nas descrições apontadas pelos autores, mais os indícios do texto de Atos, e ainda uma terceira questão, da distância do problema judaico, reconhecemos a possibilidade de Antioquia ter sido o locus da obra lucana. Essa terceira questão aponta para o fato de que no Evangelho de Lucas não há uma insistência tão grande nas questões judaicas, como há em Marcos ou Mateus, e em Atos o texto ignora a visita de Pedro narrada por Paulo em G1 2.11-14. Considerando tudo isso, Antioquia passa a ser a escolha como origem da obra lucana, próxima o bastante das demais comunidades para dialogar com as mesmas fontes, mas com ênfases diferentes. Assim, para fins de uma teoria literária de Lucas, temos um escrito que nasce a partir de diversas fontes reunidas na comunidade cristã de Antioquia, cujo texto final nasce entre 80-90 d.C.

\section{Considerações finais}

O presente artigo analisou as novas tendências da pesquisa sobre a localização dos evangelhos sinóticos. Nesse sentido, percebeu-se uma aproximação geográfica da Galileia, considerada nesse sentido o berço do cristianismo judaico. Marcos nasceu primeiro, por ocasião da guerra judaico-romana, procurando animar as comunidades que estão no meio do conflito. Neste sentido, definir sua identidade própria é importante para que a comunidade saiba como se posicionar na situação. Mateus é escrito anos depois, quando o judaísmo galilaico debate a nova situação, sem o templo e o serviço sacerdotal, e os escribas e sábios se erguem 
como autoridade perante o povo. O texto do evangelho é escrito para mostrar que os seguidores de Jesus são o verdadeiro Israel, que nasce para viver no reino de Deus instaurado na morte e ressurreição do Messias. Lucas é um texto que nasce numa comunidade de fronteira, em Antioquia, que testemunhou o conflito entre judeus e gentios desde os tempos de Paulo e Pedro. Ali, as memórias de Jesus são amalgamadas com as das igrejas que surgiram da missão para os gentios. Por isso o evangelho de Lucas não pode ser lido de forma isolada do livro de Atos.

Dessa forma, a proximidade geográfica torna os evangelhos um retrato do gênero que motivou as comunidades siro-palestinenses, com a tradição da memória sobre Jesus, escritas com nuances diferentes, segundo suas situações locais, o que é perceptível quando se estuda as perícopes de maneira sinótica. O restante da cristandade muito cedo acolheu esses escritos e decidiu incorporá-los no complexo conjunto de textos considerados inspirados para os cristãos.

\section{Referências Bibliográficas}

BAUCKHAM, Richard (Ed.). The Gospel for All Christians. rethinking the Gospel audiences. Grand Rapids, Mich.: W.B. Eerdmans. 1998.

CAMACHO, Fernando, MATEOS, JUAN. O Evangelho de Mateus. Leitura comentada. São Paulo: Edições Paulinas, 1993.

CROSLEY, James G. "The Date of Mark's Gospel: Insight from the Law in Earliest Christianity." In: Journal for the Study of the New Testament. Suplement 266, London, New York: Clark, 2004.

FITZMYER, Joseph A. El Evangelio Según Lucas. 4 tomos. Madrid: Ediciones Cristiandad, 1986.

GARCIA, Paulo R. Sábado: a mensagem de Mateus e a contribuição judaica. São Paulo: Fonte Editora, 2010.

GRANT, Frederick C. "The Gospel According to St. Mark". In: The Interpreter's Bible. Vol VII, p.630-???.

JOHNSON, Sherman E. "The Gospel According to St. Matthew". In:

Interpreter's Bible, Vol VII. New York: Abingdon Press, 1951.

KOESTER, Helmut. Introdução ao novo testamento 2. História e literatura do cristianismo primitivo. São Paulo: Paulus, 2005. 
KÜMMEL, Werner G. Introdução ao Novo Testamento. $2^{\mathrm{a}}$ ed. São Paulo: Paulus, 1985.

LIMA, Anderson de Oliveira. Acumulai Tesouros no Céu: estudo da linguagem econômica o Evangelho de Mateus. Dissertação de Mestrado em Ciências da Religião. Universidade Metodista de São Paulo, 2010.

LUZ, Ulrich. El Evangelio Según San Mateo, I. Mt 1-7. Salamanca: Ediciones Sigueme, 1993.

MARCONCINI, Benito. Os Evangelhos Sinóticos. 2a ed. São Paulo: Paulinas, 2004.

MAZZAROLO, Isidoro. O evangelho de São Mateus. Rio de Janeiro: Mazzarolo Editor, 2005.

MEEKS, Wayne A.; WILKEN, Roberts. Jews and Christians in Antioch in the First Four Centuries of the Common Era. Missoula: Scholar Press (The Society Biblical Literature), 1978.

MYERS, Ched. O Evangelho de São Marcos. São Paulo: Paulinas, 1992. NÚÑEZ, César Carbullanca. "Apuntes sobre el sentido teológico de la historia en el Evangelio de Marcos". In: Oracula 4.8 (2008). Versão online: http://www.oracula.com.br/numeros/022008/01 nunez.pdf.

OVERMAN, Andrew. O Evangelho de Mateus e o Judaísmo Formativo. O mundo social da comunidade de Mateus. São Paulo: Edições Loyola, 1997.

RUNESSON, Anders. "Rethinking Early Jewish-Christian Relations: Matthean Community History as Pharisaic Intragroup Conflict". In: Journal of Biblical Literature. Vol. 127, n.1, 2008. pp. 95-132. Versão online: http://www.jstor.org/stable/25610109.

SABIN, Marie N. Reopening the Word. Reading Mark as Theology in the Context of Early Judaism. Oxford: Oxford University Press, 2002. SCHWEIZER, Eduard. Il vangelo secondo Mateo. Brescia: Paideia Editrice, 2001.

ZETTERHOLM, Magnus. The Formation of Christianity in Antioch. A social-scientific approach to the separation between Judaism and Christianity. London, New York: Routledge, 2003. 